\title{
Pola Tanam Tumpang Sari di Desa Satar Punda Barat, Kabupaten Manggarai Timur, Provinsi Nusa Tenggara Timur
}

\section{(Intercropping Planting Pattern in West Satar Punda Village, East Manggarai Regency, East Nusa Tenggara Province)}

\author{
Marlinda Mulu*, Rudolof Ngalu, Frans Laka Lazar \\ Program Studi Pendidikan Guru Sekolah Dasar, Fakultas Keguruan dan Ilmu Pendidikan, Universitas Katolik Indonesia \\ Santu Paulus Ruteng, Jl. A. Yani No. 10 Ruteng, Flores, Nusa Tenggara Timur 86511. \\ *Penulis Korespondensi: lindamulu@gmail.com \\ Diterima September 2019/Disetujui Januari 2020
}

\begin{abstract}
ABSTRAK
Desa Satar Punda Barat memiliki potensi pertanian hortikultura yang perlu dikembangkan karena memiliki lahan yang subur, namun sebagian besar petani hanya mengenal sistem pertanian monokultur. Petani belum mengenal sistem pertanian polikultur, sehingga pendapatan petani hanya bergantung pada satu jenis tanaman pada masa panen. Keunggulan sistem pertanian polikultur adalah dapat menanam dua atau lebih jenis tanaman pada lahan yang sama serta frekuensi panen yang lebih dari satu kali. Tujuan kegiatan ini adalah memperkenalkan pola tanam tumpang sari (polikultur) dengan mengoptimalkan lahan sempit dengan menanam lebih dari satu jenis tanaman (tomat dan cabai merah) dan meningkatkan kesejahteraan petani dengan hasil panen yang hampir bersamaan antara dua jenis tanaman. Metode yang digunakan adalah teknik penyuluhan dan praktik secara langsung pada lahan contoh. Hasil kegiatan menunjukkan respons positif dan meningkatnya pengetahuan tentang pola tanam tumpang sari dari anggota kelompok tani sebesar $63 \%$ dari sebelumnya, serta meningkatnya pendapatan petani.
\end{abstract}

Kata kunci: polikultur, pola tanam, tumpang sari

\begin{abstract}
West Satar Punda Village has horticultural farming potential that needs to be developed because it has fertile land, however most farmers are only familiar with monoculture farming system. They are not familiar with the polyculture farming system, thus farmers' income depends only on one type of crop during harvest season. The advantages of polyculture farming system are it can be planted two or more types of plants on the same land and the frequency of harvest is more than once. The purpose of this program is to introduce intercropping pattern (polyculture) by optimizing land by growing more than one type of plants (tomatoes and red chili) and increasing the welfare of farmers with the nearly simultanuous harvest time of the two types of plants. The method used were extension techniques and demonstration method in a plot of sample land. The results of the program show positive responses and increased knowledge about intercropping pattern of the members of farmers group, and also increases farmer's income.
\end{abstract}

Keywords: intercropping, planting pattern, polyculture

\section{PENDAHULUAN}

Sektor pertanian merupakan salah satu sektor penting di Indonesia yang menunjang kegiatan perekonomian bangsa. Penyediaan komoditas pertanian akan memengaruhi stabilitas ekonomi suatu negara. Dewasa ini, sektor pertanian mendapatkan banyak tantangan mengenai eksistensinya dalam menunjang kehidupan masyarakat. Menurut Badan Pusat Statistik (BPS), saat ini lahan pertanian semakin tergerus akibat aktivitas ekonomi manusia, terutama untuk permukiman, pembangunan infrastruktur (jalan, bendungan, dan sebagainya), ataupun industri. Data yang dihimpun BPS menunjukkan bahwa pada tahun 2016 luas lahan baku sawah 8,18 juta ha. Pada tahun 2017 menurun menjadi 7,75 juta ha dan pada tahun 2018 menurun hingga 7,1 juta ha dari tahun sebelumnya (Kementrian Pertanian RI 2018). Hal ini menunjukan konversi lahan sawah menjadi lahan bukan pertanian meningkat setiap tahunnya.

Masalah tersebut juga dirasakan petani yang ada di Desa Satar Punda Barat, Kecamatan Lamba Leda, Kabupaten Manggarai Timur. Luas wilayah secara keseluruhan untuk lahan pertanian hanya 
sejumlah \pm 20 ha. Dari lahan tersebut yang digunakan untuk menanam tanaman hortikultura tidak mencapai setengah luas wilayah pertanian. Lahan yang digunakan hanya sebesar \pm 2 ha. Sementara itu, lahan lainnya digunakan untuk tanaman padi dan jagung serta tanaman lain. Luas wilayah pertanian yang tergolong sempit, sangat membatasi ruang gerak petani untuk mendapatkan hasil pertanian yang maksimal. Selain itu, petani di desa ini hanya mengenal pertanian monokultur, sehingga proses peralihan musim tanam dari tanaman jenis yang pertama ke jenis yang lain membutuhkan waktu yang lama.

Hasil hortikultura dari desa ini tidak hanya dimanfaatkan untuk memenuhi kebutuhan mereka sendiri tetapi juga memenuhi kebutuhan sayur di sebagian wilayah Kabupaten Manggarai dan sebagian wilayah Kabupaten Manggarai Timur. Salah satu cara yang dapat diadopsi dalam rangka memenuhi permintaaan pasar serta mengefektifkan lahan pertanian untuk meningkatkan pendapatan petani adalah dengan sistem penanaman tumpang sari. Perkembangan pola tanam tumpang sari atau tumpang gilir sayuran di dataran tinggi maupun di dataran rendah saat ini telah menjadi salah satu pilihan utama petani berlahan sempit dalam upaya mengatasi risiko kegagalan usaha taninya (Suwandi et al. 2003).

Pertanian berkelanjutan pada dasarnya merupakan suatu konsepsi menyangkut tantangan bagi produsen agar mulai mempertimbangkan implikasi jangka panjang cara budi daya, interaksi sistem usaha tani, dan dinamika sistem pertanian (Adiyoga et al. 2004). Salah satu metode yang sering digunakan dalam pertanian berkelanjutan adalah tumpang sari, hal ini bertujuan untuk mengoptimalkan lahan sempit dan meningkatkan produktivitas pertanian serta meningatkan jumlah pendapatan. Pemilihan kombinasi tanaman dapat didasarkan pada perbedaan-perbedaan sistem perakaran tanaman, kebutuhan tanaman terhadap hara dan sinar matahari ataupun cara pengendalian hama penyakit (Suwandi et al. 2003). Menurut Effendi et al. (2007), usaha tani monokultur pada lahan relatif sempit kurang menguntungkan, kegagalan panen berarti kerugian sangat besar. Polikultur dengan sistem pola tanam yang tepat dapat mengatasi kerugian akibat gagal panen dari satu jenis komoditas.

Tumpang sari merupakan pengusahaan lebih dari satu jenis tanaman pada lahan yang sama dalam barisan yang teratur sedemikian rupa sehingga menunjang pertumbuhan tanaman.
Sistem pertanaman berganda atau tumpang sari adalah definisi umum dari semua pola pertanaman yang melibatkan penanaman lebih dari satu jenis tanaman pada suatu hamparan lahan (Permanasari \& Kasatono 2012). Sistem tanam tumpang sari adalah salah satu usaha sistem tanam di mana terdapat dua atau lebih jenis tanaman yang berbeda ditanam secara bersamaan dalam waktu relatif sama atau berbeda dengan penanaman berselang-seling dan jarak tanam teratur pada sebidang tanah yang sama (Prasetyo et al. 2009). Tumpang sari merupakan salah satu bentuk dari program intensifikasi pertanian alternatif yang tepat untuk memeroleh hasil pertanian yang optimal. Keuntungan pola tanam tumpang sari selain diperoleh frekuensi panen lebih dari satu kali dalam setahun, juga berfungsi untuk menjaga kesuburan tanah (Vandermeer 1998), memberikan penutup tanah sepanjang tahun, atau paling tidak dalam periode waktu yang lebih panjang dibandingkan dengan sistem monokultur, sehingga dapat mengurangi tingkat erosi tanah, memberikan perlindungan tanaman profilastis melalui diversifikasi spesies dan varietas (Prasetyo 2003). Sistem tanam tumpang sari merupakan bagian integral dari kegiatan ekstensifikasi dan intensifikasi yang bertujuan untuk melipatgandakan hasil pangan, dan memecahkan masalah kerusakan sumber daya alam atau memperbaiki lingkungan hidup (Suwandi et al. 2003).

Adapun tujuan dari kegiatan ini adalah pertama, memperkenalkan teknik tanaman tumpang sari dengan mengoptimalkan lahan sempit dengan menanam lebih dari satu jenis tanaman (tomat dan cabai merah) yang toleran dan dapat dibudidayakan bersama. Kedua meningkatkan kesejahteraan petani dengan hasil panen yang hampir bersamaan antara dua jenis tanaman. Program pemberdayaan ini diharapkan dapat menginisiasi kelompok-kelompok tani yang ada di desa untuk menggunakan teknik tanam tumpang sari sehingga dapat meningkatkan pendapatan petani.

\section{METODE PELAKSANAAN KEGIATAN}

\section{Tempat dan Partisipan Kegiatan}

Kegiatan ini dilaksanakan di Desa Satar Punda Barat, Kecamatan Lamba Leda, Kabupaten Manggarai Timur, Nusa Tenggara Timur. Partisipan dalam kegiatan ini adalah masyarakat desa yang tergabung dalam kelompok tani 
Mangga Manis Raba yang berjumlah 20 orang. Partisipan yang mengikuti kegiatan ini berjumlah 10 orang. Lahan yang digunakan adalah lahan milik salah satu warga desa yang tergabung dalam kelompok tersebut. Lahan ini dipilih karena letaknya yang paling dekat dengan jalur irigasi sehingga tidak akan menyulitkan pelaksanaan kegiatan karena kebutuhan air dalam rangka penyiraman tanaman akan tercukupi. Selain itu, lahan ini sebelumnya juga adalah bekas pertanian hortikultura. Luas lahan yang digunakan dalam metode tumpang sari adalah seluas $\pm 800 \mathrm{~m}^{2}$.

\section{Bahan dan Alat}

Bahan yang dipakai adalah bibit lombok jenis Laba F1 dan bibit tomat jenis Servo F1, profast, diazinon, pupuk NPK, dan kalsium. Alat yang digunakan adalah hand tractor, cangkul, sekop, parang, tali, dan kayu pancang.

\section{Metode Pelaksanaan}

Tumpang sari antar tanaman tomat dan cabai merah ditanam dalam waktu yang hampir bersamaan. Artinya bahwa tanaman tomat menjadi tanaman pokok dan ditanam terlebih dahulu, sementara cabai adalah tanam sisipan yang ditanam 2 hari kemudian. Pelaksanaan kegiatan ini diawali dengan penyuluhan singkat dengan pemilik lahan dan beberapa anggota kelompok tani untuk menjelaskan tentang pola tumpang sari. Selanjutnya, diikuti dengan pendampingan petani pada proses tanam dengan lima tahapan, yaitu proses semai benih, penyiapan lahan, penanaman, perawatan tanaman, dan panen.

\section{Pengumpulan, Pengolahan, dan Analisis Data}

Proses pengamatan dilakukan mulai dari tahap penyuluhan hingga tahap panen. Keberhasilan program ini dinilai dari pengetahuan petani tentang teknik tanam tumpang sari sebelum dan sesudah kegiatan dilaksanakan. Penilaian praktik pola tanam tumpang sari dengan menilai secara deskriptif kualitatif mulai dari tahap semai benih sampai pada tahap panen dengan nilai kurang, cukup, baik, dan sangat baik. Selain itu, dengan menilai hasil panen yang diperoleh petani baik itu tanaman tomat maupun cabai merah serta keuntungan yang diperoleh dari hasil penjualan.

\section{HASIL DAN PEMBAHASAN}

\section{Pelaksanaan Kegiatan}

Desa Satar Punda Barat merupakan desa yang dikenal dengan potensi pertanian hortikultura. Masyarakat di desa ini sangat bergantung pada hasil pertanian. Sektor pertanian menjadi sektor penting bagi kehidupan di desa ini. Meskipun memiliki potensi tersebut, petani desa ini mengalami kendala seperti kurangnya sumber air untuk pengairan sawah (masih ada yang mengandalkan air dari sumur bor), sistem irigasi yang masih tradisional dan masih mengandalkan pertanian monokultur sehingga hasil panen terbatas. Pola tanam tumpang sari diperkenalkan untuk mengatasi masalah hasil panen yang terbatas dan diyakini dapat meningkatkan kesejahteraan petani. Penjelasan Pola tanam tumpang sari tentang cara, manfaat serta kelebihan tumpang sari dilakukan oleh tim pelaksanaan kegiatan melalui penyuluhan singkat dengan pemilik lahan dan beberapa anggota kelompok tani. Fokusnya adalah pendampingan kepada individu dan kelompok, sehingga apabila pengerjaan pada lahan contoh ini berhasil maka proses transfer ilmu kepada anggota kelompok menjadi lebih mudah ketika secara langsung melihat proses awal dan hasil akhir kegiatan ini.

Proses tanam dan pengerjaan meliputi tahapan sebagai berikut:

- Tahap semai benih. Proses penyemaian ini tidak menggunakan papan semai/polibag tetapi langsung disemai pada tanah humus dengan ukuran $\pm 15 \mathrm{~m}^{2}$, yang telah dipersiapkan sebelumnya. Setelah benih disemai, maka dilakukan penyiraman setiap hari pada waktu pagi dan sore selama 4-6 minggu. Tujuannya untuk menjaga kelembapan tanah agar benih cepat tumbuh dan berkembang. Benih yang telah disemai tersebut dilindungi dari sinar matahari langsung dengan menggunakan penutup khusus (daun kelapa). Tujuannya agar melindungi tanaman muda yang masih rentan dengan cahaya matahari langsung. Gambar 1 menunjukkan tempat semai yang sudah disemai dengan benih.

- Penyiapan lahan. Pada tahap ini diawali dengan pembersihan lahan dari gulma atau sisa tanaman sebelumnya. Setelah dibersihkan, lahan kemudian digemburkan sehingga memudahkan sistem perakaran tanaman 


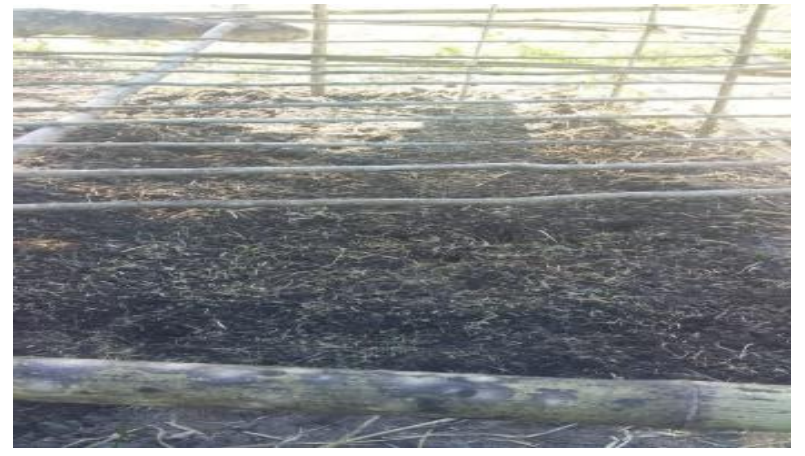

Gambar 1 Tempat semai yang sudah disemai benih.

untuk masuk ke dalam tanah dan menyerap unsur hara. Setelah tekstur tanah berubah akibat proses penggemburan maka selanjutnya pembuatan lajur-lajur untuk tanam. Setiap lajur memiliki lebar $1 \mathrm{~m}$ dengan tinggi $15 \mathrm{~cm}$. Setiap lajur yang dibentuk kemudian ditambahkan pupuk organik (kompos) yang telah dibuat sebelumnya. Penambahan pupuk kompos ini bertujuan menjamin kebutuhan hara tanaman sejak awal tumbuh. Gambar 2 menunjukkan kegiatan penyiapan lahan.

- Tahap penanaman. Setelah usia bibit tomat dan cabai mencapai usia 4-6 minggu atau memiliki 4-6 helai daun, maka bibit tersebut siap untuk ditanam (Gambar 3). Proses penanaman berlangsung selama 4 hari, yang diawali dengan menanam tanaman tomat pada lajur bagian luar/pinggir lajur dan pada bagian tengah lajur ditanami cabai. Setiap lubang tanam terlebih dahulu ditaburi pupuk khusus dengan takaran \pm 1 sendok teh pupuk. Tujuannya untuk mengatasi ulat pada akar yang mungkin akan muncul dan merusak sistem perakaran. Jumlah tanaman tomat yang ditanam adalah 500 pohon dan cabai merah berjumlah 750 pohon. Gambar 4 menunjukkan lahan yang sudah ditanamai dengan bibit tomat dan cabai.

- Tahap perawatan tanaman. Pada tahapan ini sangat diperhatikan kebutuhan unsur hara tanaman. Kebutuhan akan hara ini dipenuhi melalui penyiraman pupuk NPK (nitrogen, fosfor, dan kalium) yang dicampur dengan kalsium. Penyiraman pupuk ini telah dilakukan saat tanaman berusia 14 hari setelah tanam dan berjarak 10 hari dengan pemupukan berikutnya. Selain memerhatikan kebutuhan hara, hal lain yang diperhatikan adalah gulma yang mungkin tumbuh dan mengganggu pertumbuhan tanaman karena setiap lajur tanam tidak tertutup mulsa, maka akan rentan dengan gulma. Oleh karena itu, setiap 2 minggu sekali dilakukan penyiangan

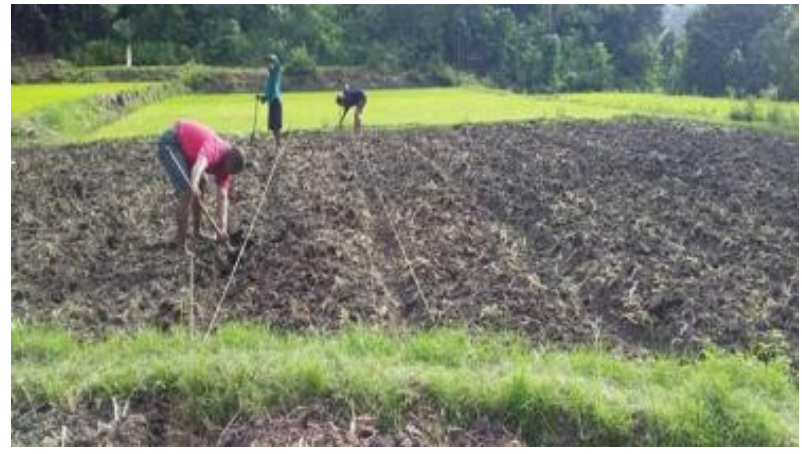

Gambar 2 Kegiatan penyiapan lahan.

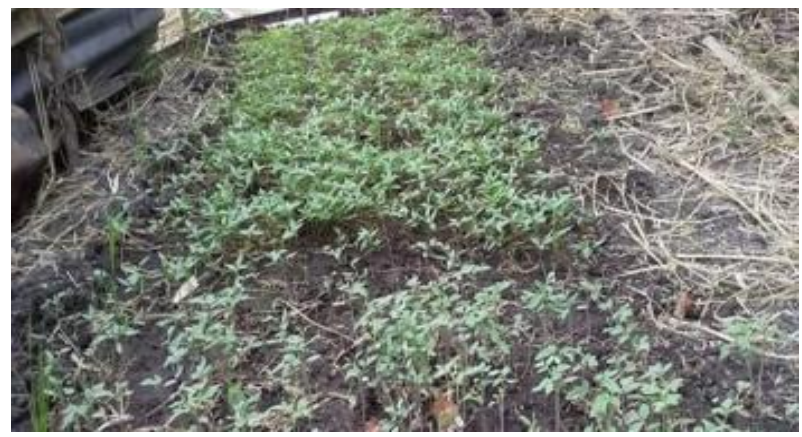

Gambar 3 Anakan tomat dan cabai siap ditanam.

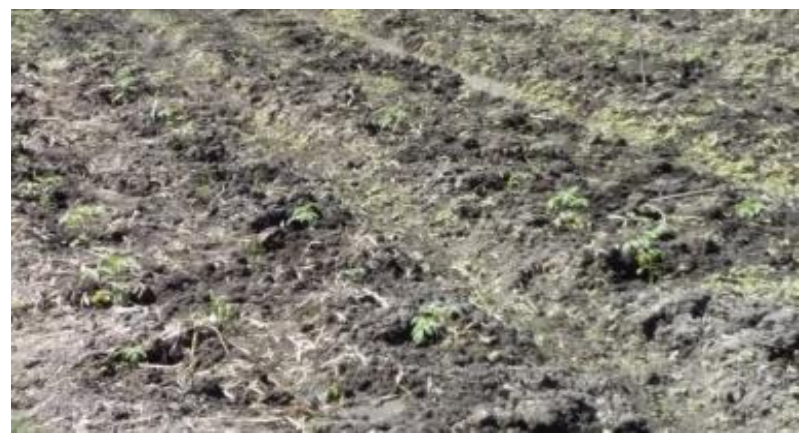

Gambar 4 Lahan yang sudah ditanami dengan bibit tomat dan cabai.

tanaman (mencabut gulma dan menggemburkan tanah di sekitar daerah akar). Proses ini dilakukan sampai masa panen tiba. Gambar 5 menunjukkan perkembangan tanaman dari usia 10-60 hari.

- Tahap panen. Usia tanaman siap dipanen berkisar 70 hari. Tanaman tomat menunjukan pertumbuhan yang lebih cepat dibandingkan tanaman cabai, hal ini dikarenakan usia tanaman lebih singkat. Dalam satu pohon tanaman tomat terdiri dari 2-4 cabang utama dan masing-masing cabang dapat menghasilkan 4-5 tangkai. Masing-masing tangkai terdiri dari 5-9 buah tomat. Sementara itu, pada tanaman cabai merah dalam satu pohon dapat menghasilkan 50-60 buah. Hasil panen tanaman cabai dan tomat terlihat pada Gambar 6. 

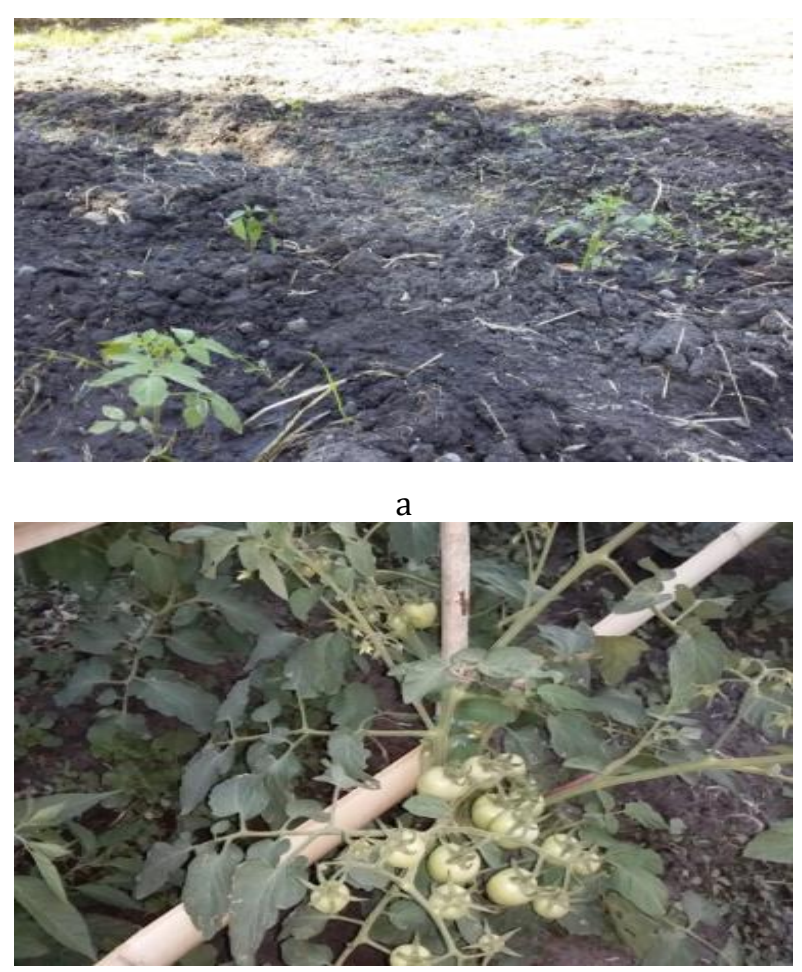

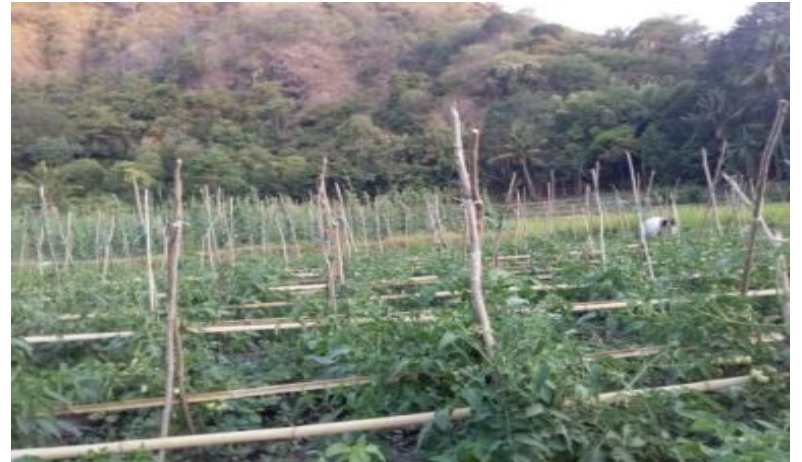

$\mathrm{b}$

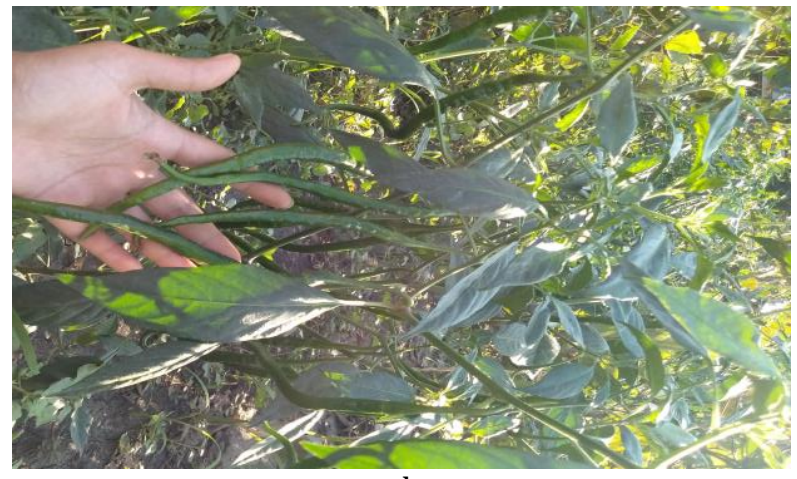

$\mathrm{d}$

Gambar 5 Perkembangan tanaman dari usia 10-60 hari: a) Tanaman tomat usia 10 hari; b) Tanaman tomat usia 30 hari; c) Tanaman tomat usia 40 hari; dan d) Tanaman cabai usia 60 hari.

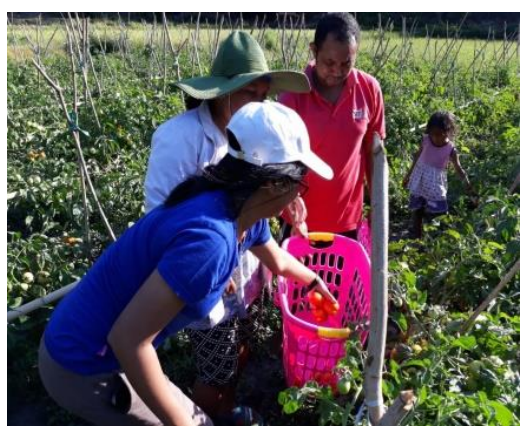

a

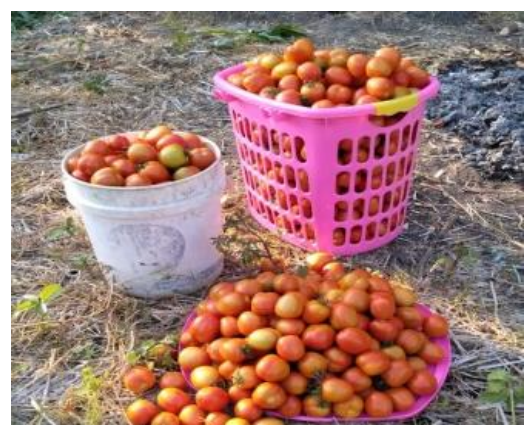

b

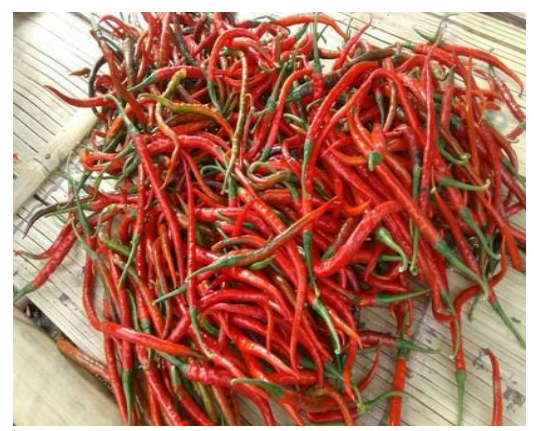

Gambar 6 Hasil panen tanaman cabai dan tomat; a) Pemanenan tomat; b) Tomat hasil panen; dan c) Cabai hasil panen.

\section{Analisis Hasil Kegiatan}

Hasil kegiatan pengabdian ini ditunjukkan dengan peningkatan pengetahuan anggota kelompok tani yang terlibat dan keberhasilan memanen tanaman tomat dan cabai dengan teknik tanam tumpang sari. Selain diperkenalkan teknik tumpang sari, tim juga memberikan arahan mengenai proses pemupukan yang benar. Berdasarkan hasil kegiatan diperoleh peningkatan pengetahuan petani dari sebelum dan setelah kegiatan sebesar 63\% (Tabel 1). Hasil ini menunjukan pemahaman petani tentang teknik tanam tumpang sari mengalami peningkatan.

Total bobot keseluruhan tanaman tomat setelah semuanya dipanen adalah $1.500 \mathrm{~kg}$. Setiap pohon tomat rata-rata menghasilkan $3 \mathrm{~kg}$.
Sementara pada cabai merah berjumlah $150 \mathrm{~kg}$ dan setiap pohon rata-rata menghasilkan $0,2 \mathrm{~kg}$. Proses pemanenan tomat dilakukan 2 hari sekali, sementara cabai merah 5-7 hari sekali bergantung proses pematangan buah. Hasil positif yang diperoleh pada kegiatan ini sejalan dengan hasil penelitian Suwandi et al. (2003) yang menunjukkan bahwa tanaman cabai yang menjadi tanaman sisipan tidak mengganggu tanaman pokok. Hasil buah tomat yang dapat dipasarkan tertinggi dihasilkan tumpang sari tanaman tomat dengan cabai dalam barisan tanam (dengan jarak tanam) di mana tanaman cabai berperan sebagai tanaman sisipan (dua minggu setelah tomat) dan nyata lebih tinggi dibandingkan dengan hasil pertanaman tomat monokrop. 
Tabel 1 Hasil evaluasi peningkatan pengetahuan tentang teknik tumpang sari

\begin{tabular}{lrr}
\hline \multicolumn{1}{c}{ Aspek yang dinilai } & \multicolumn{2}{c}{ Peningkatan pengetahuan } \\
\cline { 2 - 3 } & Sebelum (\%) & Sesudah (\%) \\
\hline Pemahaman teknik tumpang sari/pertanian polikultur & 5 & 100 \\
Manfaat teknik tumpang sari/pertanian polikultur & 20 & 70 \\
Proses tanam teknik tumpang sari & 0 & 80 \\
Proses pemupukan tanaman & 60 & 100 \\
Kelebihan dan kekurangan teknik tumpang sari & 20 & 70 \\
Rata-rata & 21 & 84 \\
\hline Peningkatan & 0 & 63 \\
\hline
\end{tabular}

Proses pemanenan mengalami peningkatan sejak pertama kali panen, rata-rata peningkatan tomat berkisar $20 \mathrm{~kg}$ setiap 2 atau 3 hari panen, sedangkan pada cabai peningkatannya $5 \mathrm{~kg}$ setiap 4 atau 5 hari panen. Pada tomat panen melimpah diperoleh pada masa panen 3-8 dan pada cabai 3-6 masa panen.

Selain hasil panen yang dinilai sangat baik, respons positif juga diperoleh dari anggota kelompok tani dan warga desa setelah mereka melihat keberhasilan program pengabdian ini. Selanjutnya adalah mengevaluasi setiap tahapan yang dilalui sejak awal sampai masa panen berakhir dengan cara menghitung laba yang diperoleh. Tabel 2 menunjukkan evaluasi kegiatan pasca tanam dan panen dan Tabel 3 menunjukkan evaluasi setiap tahap kegiatan.

\section{Kendala yang Dihadapi}

Kendala yang dihadapi tim pada saat melakukan kegiatan ini adalah tidak semua anggota kelompok tani antusias dalam mengikuti program pemberdayaan ini. Hal ini dikarenakan kesibukan dan sikap ragu atas keberhasilan sistem pertanian polikultur. Untuk mengatasi ini maka, tim memutuskan untuk terlebih dahulu memberi contoh melalui kerja sama dengan salah satu warga pada kelompok tani sekaligus menggunakan lahan miliknya.

Selain itu, proses semai benih juga tidak menggunakan polibag/papan semai, sehingga tidak semua bibit yang disemai dapat tumbuh. Kendala lain yang juga dihadapi adalah debit air yang berkurang pada musim kemarau pada saluran irigasi tradisional. Oleh karena itu, untuk memenuhi kebutuhan air, proses penyiraman ini dibantu dengan air dari sumur bor di sekitar lahan tanam.

\section{Dampak Kegiatan Pengabdian}

Dampak nyata yang diperoleh dari kegiatan ini, bagi mitra adalah meningkatnya hasil panen. Lahan yang sebelumnya hanya menghasilkan satu jenis tanaman, saat ini dapat ditanam
Tabel 2 Evaluasi kegiatan pascatanam dan panen

\begin{tabular}{lll}
\hline \multicolumn{1}{c}{$\begin{array}{c}\text { Aspek yang } \\
\text { diamati }\end{array}$} & \multicolumn{1}{c}{ Tomat } & Cabai merah \\
\hline $\begin{array}{l}\text { Tinggi tanaman } \\
\text { Jumlah buah pada }\end{array}$ & $\begin{array}{l}100-120 \mathrm{~cm} \\
\text { 1 pohon }\end{array}$ & $60-65 \mathrm{~cm}$ \\
$\begin{array}{l}\text { Bobot buah pada } \\
1 \text { pohon }\end{array}$ & $\pm 3 \mathrm{~kg}$ & 0,60 \\
$\begin{array}{l}\text { Jumlah } \\
\text { panen hasil }\end{array}$ & $1500 \mathrm{~kg}$ & $150 \mathrm{~kg}$ \\
$\begin{array}{l}\text { Hasil penjualan } \\
\text { Biaya produksi } \\
\text { total Rp 7.500.000 }\end{array}$ & & $\mathrm{Rp} \mathrm{3.750.000}$ \\
\hline Laba & & $\mathrm{Rp} \mathrm{2.000.000}$ \\
\hline
\end{tabular}

Tabel 3 Evaluasi setiap tahap kegiatan

\begin{tabular}{ll}
\hline \multicolumn{1}{c}{ Aspek yang dinilai } & \multicolumn{1}{c}{ Keterangan } \\
\hline Semai benih & Cukup Baik \\
Penyiapan lahan & Sangat baik \\
Penggunaan pupuk organik & Baik \\
Penanaman & Sangat baik \\
Perawatan dan pemupukan & Sangat baik \\
Pemanenan & Sangat baik \\
\hline
\end{tabular}

dengan dua jenis tanaman yang toleran. Akibatnya, petani dapat memanen lebih dari satu jenis tanaman dalam sekali masa panen.

\section{Upaya Keberlanjutan Kegiatan}

Upaya berkelanjutan yang dilakukan setelah kegiatan ini adalah melakukan pendampingan dan monitoring secara terus menerus baik bersifat individu maupun kelompok bagi petani hortikultura. Tujuannya agar pengetahuan tentang pertanian polikutur semakin meningkat, kualitas produksi juga tetap terjaga. Selain itu, tim bekerjasama dengan petani pemilik kebun contoh untuk memberikan pendampingan pada anggota kelompok tani lain ataupun warga desa tersebut.

\section{SIMPULAN}

Pelaksanaan program pengabdian di Desa Satar Punda Barat, kabupaten Manggarai Timur 
Provinsi Nusa Tenggara Timur melalui pola tanam tumpang sari ini telah memberi kesempatan kepada petani untuk mengetahui dan memahami tentang pola tanam tumpang sari sebagai bagian dari pertanian polikultur dengan peningkatan pengetahuan sebesar 63\%. Selain itu petani juga dibekali dengan pengetahuan tambahan mengenai pentingnya pupuk organik serta cara pemupukan yang benar. Program ini juga berhasil meningkatkan kesejahteraan petani dari sebelumnya. Hasil produksi pertanian dan keuntungan yang meningkat merupakan indikasi keberhasilan program ini. Lahan sempit dan terbatas yang pada awalnya ditanami satu jenis tanaman, kini dapat ditanam dengan dua jenis tanaman.

\section{DAFTAR PUSTAKA}

Adiyoga W, Suherman R, Gunadi N, Hidayat A. 2004. Aspek Nonteknis dan Indikator Efisiensi Sistem Pertanaman Tumpang Sari Sayuran Dataran Tinggi. Jurnal Hortikultura. 14(3): 17.

Effendi DS, Taher S, Rumini W. 2007. Penaruh Tumpang sari dan Jarak Tanam terhadap Pertumbuhan dan Hasil Tanaman Jarak Pagar
(Jatropha curcas L.). Bogor (ID): Pusat Penelitian dan Pengembangan Perkebunan.

Kementrian Pertanian RI. 2018. Statistik Data Lahan Pertanian. Jakarta (ID): Departemen Pertanian.

Permanasari I, Kastono D. 2012. Pertumbuhan Tumpang sari Jagung Dan Kedelai Pada Perbedaan Waktu Tanam Dan Pemangkasan Jagung. Jurnal Agroteknologi. 3(1): 13-20.

Prasetyo, Sukardjo EI, Pujiwati H. 2009. Produktivitas Lahan dan NKL pada Tumpang Sari Jarak Pagar dengan Tanaman Pangan. Jurnal Akta Agrosia. 12(1): 51-55.

Prasetyo. 2003. Pengaruh Pemupukan Nitrogen Dan Fosfor Terhadap Pertumbuhan Tanaman Kapulaga sebagai Tanaman Sela Pada Dua Umur Tegakan Sengon. [Disertasi]. Malang (ID): Universitas Brawijaya.

Suwandi R, Rosliani N, Sumarni, Setiawati W. 2003. Interaksi Tanaman pada Sistem Tumpang sari Tomat dan Cabai di Dataran Tinggi. Jurnal Hortikultura. 13(4): 244-250.

Vandermeer J. 1998. Maximizing Crop Yield in Alley Crops. Agroforestry Systems. 40: 199206. 